\title{
Zinc Oxide Bulk Wave Transducers
}

\section{Larson, John D.}

\section{Published in:}

2nd European Microwave Conference

Link to article, DOI:

10.1109/EUMA.1971.331542

Publication date:

1971

\section{Document Version}

Publisher's PDF, also known as Version of record

Link back to DTU Orbit

\section{Citation (APA):}

Larson, J. D. (1971). Zinc Oxide Bulk Wave Transducers. In 2nd European Microwave Conference (Vol. Volume 2, pp. 1-5). IEEE. https://doi.org/10.1109/EUMA.1971.331542

\section{General rights}

Copyright and moral rights for the publications made accessible in the public portal are retained by the authors and/or other copyright owners and it is a condition of accessing publications that users recognise and abide by the legal requirements associated with these rights.

- Users may download and print one copy of any publication from the public portal for the purpose of private study or research.

- You may not further distribute the material or use it for any profit-making activity or commercial gain

- You may freely distribute the URL identifying the publication in the public portal

If you believe that this document breaches copyright please contact us providing details, and we will remove access to the work immediately and investigate your claim. 
ZINC OXIDE BULK WAVE TRANSDUCERS

JOHN D. LARSON

PHYSICS LABORATORY III, TECHNICAL UNIVERSITY OF DENMARK

\section{INTRODUCTION}

We wish to report the use of rf sputtered films of zinc oxide ( $\mathrm{znO})$ for microwave acoustic transducer use. We have diode sputtered $\mathrm{zno}$ from the compound in an argon/oxygen atmosphere. Insulating films from 2 to 7 microns thick were deposited on gold electrode layers on single crystal sapphire. Deposition rates as high as $1.6 \mu \mathrm{m}$ per hour have been achieved with 1.0 to $1.5 \mu \mathrm{m} / \mathrm{hr}$ typical. By $\mathrm{x}$-ray analysis, we find the films to be oriented with the c-axis essentially normal to the substrate.

These films were used as longitudinal acoustic wave transducers. Untuned insertion loss measurements were made over the frequency interval 0.1 to $4 \mathrm{GHz}$. By curve fitting the calculated response to the measured, we have usually obtained values of the electroacoustic coupling constant $k_{t}$ in the range 0.20 to 0.25 . For bulk material, $k_{t}$ is 0.282 (see (1)).

Sputtering $(2,3)$ has become a common process for depositing thin films of metals or dielectrics on a desired substrate.

Radio frequency ( $r f$ ) diode (4) sputtering is especially useful since one can readily work at pressures of a few millitorr, and can more easily excite and contain an rf plasma discharge than a dc discharge. For these reasons and the ease of control which may be exercised, we have investigated and found that $r f$ sputtering is a suitable means for depositing piezoelectrically active layers of 7 no.

In Fig. 1 is shown a schematic diagram of the sputtering apparatus. It employs a commercially available $15.2 \mathrm{~cm}$ diameter cathode assembly. Pre-mixed argon/oxygen is admitted to the bell jar through a precision leak valve. The bell jar is pumped by a 450 liter/sec oil diffusion pump with a liquid nitrogen cold trap. The diffusion pump is throttled to maintain the pump pressure below 1 militiorr. The cathode and anode assemblies are both water cooled. The substrate holder is provided with both a heater for bakeout prior to sputtering and water cooling to hold the specified substrate temperature during sputtering.

A plasma is excited between cathode and anode assemblies by a $13.56 \mathrm{MHz}$ rf source. The Zno target assumes a negative bias due to a blocking capacitor between the cathode and rf source. Positive ions from the plasma bombard the negatively biased target, thus sputtering off $\mathrm{Zno}$.

Laser monitoring (5) is employed to determine the film thickness during deposition. Experimentally, we find that for laser light of wavelength $\lambda_{0}=0.6328 \mu \mathrm{m}$, the calibration factor is $0.161 \mu \mathrm{m}$ for each fringe, i.e., the interval between two successive maxima of the interference pattern.

Due to the concentric design of the cathode assembly, we were obliged to place the substrate off center in order to perform laser monitoring. We have not detected any significant variation in film thickness over substrate areas of 0.5 by 0.5 $\mathrm{cm}$ due to this effect. However, it was found that placing a 


\section{6/5:2}

metallic mask with a $0.2 \mathrm{~cm}$ diameter hole over the substrate resulted in a film whose thickness varied drastically from edge to center. This variation was apparent from a series of interference rings observed in the Zno film after deposition. Instead of masking, the desired geometry was obtained by etching away the undesired portions of the film after deposition. The etchant used was one part $\mathrm{HCl}$ in five parts water.

Thin films of ZnO were sputtered under many conditions. We have found the set of parameters in Table I to produce reasonably good and consistent results:

Gas

Bell jar pressure Cathode-anode spacing Cathode-anode self bias Substrate Temperature RF power
$80 \%$ argon $/ 20 \%$ oxygen pre-mixed $8 \times 10^{-3}$ Torr (ion gauge monitor) $3.8 \mathrm{~cm}$ 1600 to 2000 volts $200^{\circ} \mathrm{C}$ 300 to 500 watts.

Table I - Sputtering Parameters

Under these conditions, a depostion rate of 1.0 to $1.6 \mu \mathrm{m}$ per hour is obtained.

The effect of varying parameters is now considered. In Fig. 2 is shown the deposition rate of $\mathrm{znO}$ vs cathode-anode self bias voltage. The gas pressure, substrate temperature, and cathode-anode spacing are held constant at the values shown in Table I. We find a linear dependence of deposition rate on cathode-anode voltage.

The pressure of the sputtering gas was varied from 5 milliTorr to 30 millitorr and the sputtering rate was observed. It was found to vary from $0.7 \mu \mathrm{m} /$ hour to $1.1 \mu \mathrm{m} /$ hour over this pressure range for a fixed rf power input.

Two different compositions of the sputtering gas were tried. When pure argon was used, we obtained conducting material with a resistivity in the range of $500 \mathrm{ohm}-\mathrm{cm}$ and relatively poor generation of acoustic waves.

When the $80 \%$ argon - 20\% oxygen mixture was used, we obtained insulating $\mathrm{ZnO}$ ( $\rho>5$ megohm-cm) which generally exhibited good piezoelectric properties.

Different substrate temperatures were tried. It was found that temperatures in the range of $150^{\circ}$ to $300^{\circ} \mathrm{C}$ produced acceptable films. Most of our runs were done at $200^{\circ} \mathrm{C}$.

\section{PHYSICAL PROPERTIES OF RF SPUTTERED ZnO}

The resulting films were found to be insulating, usually transparent, and pin-hole free. Some of the films were not completely transparent, but appeared cloudy. These films generally exhibited an inactive layer.

The crystalline structure of several films was analyzed. Using an $x$-ray diffractometer operating with copper radiation $(\lambda=1.5418 \AA)$, we find strong reflection at a d value of $2.602 \AA$, corresponding to reflection from the (0002) or basal plane (8) of $\mathrm{Zno}$. We also weakly detected the (1000) line which indicates that the crystal is not entirely oriented with the c-axis perpendicular to the surface.

\section{ACOUSTIC TRANSDUCER PROPERTIES}

All the Zno films were deposited on half wavelength $(\lambda / 2)$ 


\section{C $6 / 5: 3$}

thick back electrode layers of gold evaporated on c-axis sapphire substrates. The $\mathrm{Zno}$ and gold layers were designed to be $\lambda / 2$ thick at $\mathrm{f}_{0}=0.9 \mathrm{GHz}$. Evaporated top contacts were used to insure good Contact to the piezolayer, specifically to eliminate any series air gap capacity. The top contact diameter was chosen to obtain a capacitive reactance of 50 ohms at $\mathrm{f}_{0}$.

To evaluate the resulting Zno films, the untuned, 2-way insertion loss was measured using the pulse-echo technique. The measured insertion loss includes two transductions through the piezoelectric, the round trip acoustic attenuation, and the round trip diffraction loss. The electroacoustic coupling constant $k_{+}$is obtained by using it as an adjustable parameter to match the calculated and measured insertion loss vs frequency curves. One transduction through the piezoelectric is referred to as the conversion loss and is computed from the Mason equivalent circuit (9).

The chief difficulty encountered was that many of the films exhibited piezoelectrically inactive layers 0.2 to $1 \mu \mathrm{m}$ thick which grew on top of the active layer. The inactive layer was detected by the presence of extra poles of insertion loss within the normal acoustic bandpass. These poles are the result of mass loading. From mass loading theory (12), assuming the inactive $\mathrm{ZnO}$ loading layer to have the same acoustic impedance as the piezoelectrically active layer, and the definitions for the insertion loss poles of Fig. 3, we obtain the formulae shown in Fig. 3 for the frequencies of these poles as functions of the active and inactive layer thicknesses.

Fig. 4 shows the measured insertion loss vs frequency for a transducer which had been continuously deposited for the first $14 \frac{1}{2}$ fringes of thickness. The plasma discharge was shut off. Twelve minutes later, the discharge was re-established and an additional $0.29 \mu \mathrm{m}$ was deposited. The calculated curves were obtained assuming an inactive layer of $0.35 \mu \mathrm{m}$ in good agreement with the expected value of $0.29 \mu \mathrm{m}$. A value of $k_{t}=0.25$ is obtained indicating that this piezolayer was of high quality. The film was found to be insulating. Thus we conclude that a possible cause of an inactive layer is a discontinuity in the sputtering process.

A second source of the inactive layer appears to be contaminants, such as water vapor, which may be present during deposition. In another run, contaminants were released during the run by warming the cold trap. Based on the time of release, a layer $0.81 \mu \mathrm{m}$ thick was expected, while the insertion loss measured value was $0.74 \mu \mathrm{m}$, in very good agreement.

Fig. 5 shows an example of a transducer with no inactive layer. An .018 inch diameter top electrode was chosen to give a device reactance of 50 ohms. The measured, untuned, 2-way insertion loss was $24 \mathrm{~dB}$. From the preceding we fit theory and experiment to obtain $\mathrm{k}_{t}=0.25$. The film was insulating.

The principle result of this investigation is that piezoelectrically active zno thin films may be grown by rf diode sputtering. Deposition rates of $1 \mu \mathrm{m} /$ hour or higher have been obtained. Films as thick as $7 \mu \mathrm{m}$ have been successfully grown if the depostion is carried out in an oxygen enriched argon sputtering environment. Electroacoustic coupling constants of 0.20 , or $71 \%$ of bulk, have been consistently obtained. Anomalous inactive layers of $\mathrm{Zno}$ under certain conditions are observed to grow on top of the active layer. These inactive layers give rise to extra poles of insertion loss and cause a distortion of the acoustic bandshape. Possible causes of these layers are contaminants present during growth and discontinuities in the sputter- 
ing process. Inactive layers may be avoided by careful attention to vacuum system cleanliness and operating under ultrahigh vacuum conditions. Laser monitoring has been shown to be highly effective in obtaining precise layer thickness. Practical devices may be fabricated with this technique.

\section{REFERENCES}

1. H. Jaffe, D.A. Berlincourt, Proc. IEEE 53, 1372-85, (1965).

2. G.K. Wehner, "Sputtering by Ion Bombardment", Advances in Electronics and Electron Physics, Vol. VII, Academic Press, New York, (1955) pp. 239-298.

3. G.S. Anderson, W.N. Mayer, G.K. Wehner, J. Appl. Phys. 33, 2991, (1963).

4. J.L. Vossen, J.J. O'Neill Jr., RCA Review 28, 149, (1968).

5. R.M. Malbon, F. Schulenburg, D.K. Winslow, Microwave Laboratory Report No. 1473, Stanford University, (1966).

6. T.B. Bateman, J. Appl. Phys. 33, 3309-12, (1962).

7. N.F. Foster et al., IEEE Trans. Son. and Ultra., SU-15, $28-41$, (1968).

8. J.V. Smith, Ed., X-Ray Powder Data Files, Sets 1-5, Amer. Soc. for Testing Materials, 1916 Race St., Philadelphia, Pa., (1960).

9. D.A. Berlincourt, D.R. Curran, H. Jaffe, Physical Acoustics, W.P. Mason, Ed., Vol. 1A, Academic Press, New York, (1964), pp. 233-242.

10. R.A. Wilson, H.J. Shaw, D.K. Winslow, J. Appl. Phys. 36, 3269 , (1965).

11. E.P. Papadakis, J. Acoust. Soc. Amer., 40, 863-876, (1966).

12. J.D. Larson, T.M. Reeder, D.K. Winslow, IEEE Group MTT-18, $602,(1970)$. 


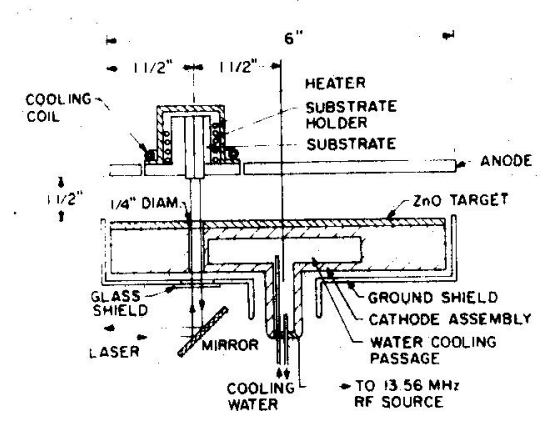

Fig. 1 - Schematic of Sputtering Apparatus.

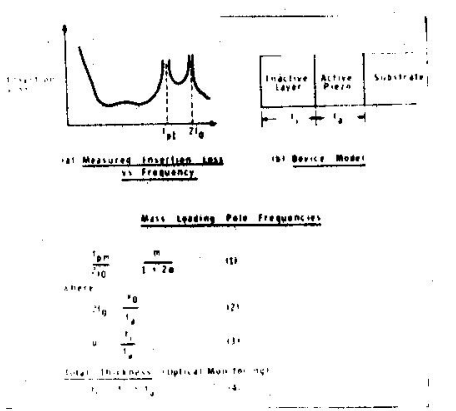

Fig. 3 - Illustrating The Effect of Inactive Layers on Device Response.

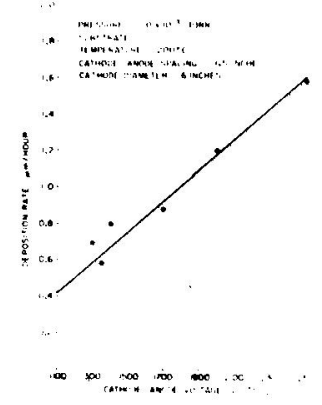

Fig. 2 - Deposition Rate vs Bias voltage.

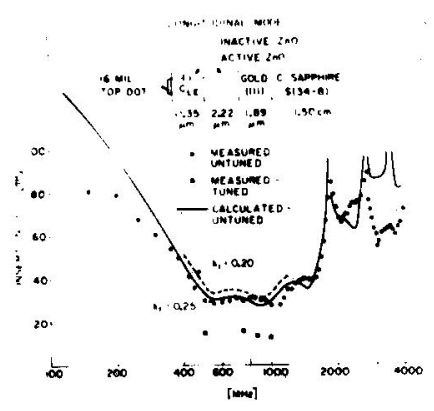

Fig. 4 - Frequency Response of Device Exhibiting An Inactive Layer.

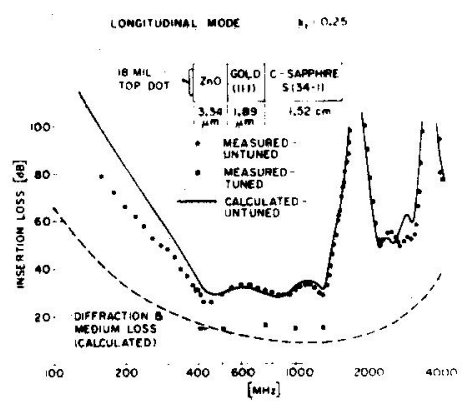

Fig. 5 - Frequency Response

For A Normal Device. 